\title{
COMBATING PANDEMICS AND SOCIAL INTERACTION ERRORS - MOVIES VERSUS REALITY
}

\author{
Ioana-Flavia DR $\breve{A G O I A N U, ~}$ \\ Bachelor's degree student in Security Studies, Faculty of Political Science, \\ University of Bucharest \\ E-mail: flaviadragoianu@yahoo.com
}

\begin{abstract}
One of the major security threats Humankind was confronted with, along several millennia, was coping with deadly viruses. In such a situation, different means of protection of the population have been ensured - medical discoveries, vaccines, and social interaction obstructions. As the creativity of man knows no bounds, different scenarios have emerged regarding combating disease whilst many scientists have designed layouts of coping with deadly viruses, using different models of infections. The goal of this paper is to analyze some of these models, through the lens of Security Studies and Political Science. Then, the discussion will shift towards social interactions and manipulating the social network. Furthermore, we will apply this model on a few selected movies, critically comparing them to the reality we are facing today. Thereby, the focus shall shift towards four well known movies: Contagion (2011), Outbreak (1995), Quarantine (2008), It comes at Night (2017) and their approach to containing and curing viruses, while also quenching the impeding chaos of dismay.
\end{abstract}

Keywords: pandemics; chaos; social interaction; social network; exclusion.

\section{Introduction}

To understand how a pandemic and an infectious disease work, I deem important an understanding of these terms. The first use of the word pandemic belongs to a Dutch physician, Gideon Harvey, who in 1674 wrote "Morbus anglicus or a theoretic and practical discourse of consumptions and hypochondriac melancholy" and later, the erm was used in 1828 by Noah Webster in the "American Spelling Book". (Cavaillon, 2021, 1-2)

During ancient times, people were not able to determine the causes of disease. Thus, disease became both a cause of divine punishment in the eyes of some and an unknown force of calamity in the eyes of others. The Great Pestilence (Cocoliztli epidemic) is considered one of the deadliest outbreaks of all times, but its cause remains a mystery over five hundred years later, as no known pathogens match the symptoms. The inevitability of disease has been a farreaching subject: from depictions of skeleton-like figures claiming the lives of beings to stories of pandemics and their unescapable grasp. (For instance, The Masque of the Red Death by Edgar Allan Poe). It is certain that it has become an important aim of mankind - to discover, analyze and eradicate such a substantial threat to human security. Not understanding the cause and the "mechanism" behind sickness, humans developed strategies of defending themselves against unseen dangers. Masks, isolation, quarantine and eventually vaccines became the foundation of preventing or stopping outbreaks right in their tracks.

Finally, as long as development is possible, new threats to the welfare of humanity come to light - one such threat is the continuous advancement of diseases. Its emergence has been a constant in history and for as long as we know, it has always seemed like an invisible and unstoppable threat. One of the main agents of infection is the spread through pathogens belonging to animals, that further sustain human-to-human transmission. 
STRATEGIES XXI International Scientific Conference

The Complex and Dynamic Nature of the Security Environment

\section{The world we know and the social network}

Further, we will be discussing some hypothesis that will become our basis in judging the accuracy with which measures of combating a pandemic is portrayed in movies.

Social interaction is unmistakably one of the necessities a human requires - but it is always the fastest way through which a virus can spread. I consider it relevant to evoke the model of Daniel Bernoulli, due to the fact that he can be considered the first to use a different equation in order to deduce formulae, leading him to the idea of statistical hypotheses in order to create models for various premises. (Sheynin, 1977, 105) He divided the population into two categories: susceptible (the ones yet to be infected) and immunes (the ones who are immune all their lives). Only a part of the entire population survives to become immune, and the percentage varies in accordance to the disease. The probability of surviving is inversely proportional with the death rate and the force of the pathogen, but there are other factors that come into equation such as age, other infections already present and susceptibility. Although the mathematic models of Bernoulli are focused on smallpox, they represented an important tool in understanding infectious disease epidemiology.

A more recent study is the one Laura Glass started as a fourteen years old girl. She used an agent-based model to describe how a disease spreads using a detail of vital importance social interaction. Influenza became her and her fathers, Robert Glass' focus, as a relatively common infectious disease and a pliable subject of research. I find their study more relevant due to the possibilities they subject in their work, analyzing not through mathematical notions but through the eyes of a modern and observing onlooker.

Social networking opens a whole world of possibilities, as it is formed by groups of people who can easily infect each other, especially given the fact that one person may belong to more than one group. Taking the case of Influenza, an infected person can become infectious in presymptomatic state or in an infectious asymptomatic state. (Glass, 2006, 1672) and having contact with the outside world keeps the circle of infections complete, as asymptomatic carriers can possibly infect others without realizing. However, a symptomatic person more often than not becomes immune, but in some cases, may even die.

The pair deems teenagers and children as the most important chess piece. During their studies for influenza as infectious as 1957-58 Asian flu ( $\approx 50 \%$ infected), closing schools and keeping children and teenagers at home reduced the attack rate by $>90 \%$. (Glass, 2006, 1671) This statement opens a new hypothesis to be put to analysis - how the social network changes and how we can manipulate it in case of a pandemic. One way through which we can slow down a pandemic is by exclusion - as long as an infected person does not have contact with others in the network, they cannot infect further. This happens through the severing of the individual from the network. Consequently, social distancing becomes an important practice but also a challenge. Its purpose is to control the spread of the disease until a better solution, like inoculation, is present. But what happens when not even seclusion can be upheld?

This leads us to another important premise - how much of a Superspreader is behavioral misconduct and how much is a genetic outcome. As mentioned earlier, from the dawn of time humanity has tried combating disease through different methods. A representative case took place in the fourteenth century, when people tried to control the spread of the Black Death through quarantining, socially distancing and wearing masks (for instance, the beaked masks filled with strong-smelling flowers, such as lavender). However, during present day COVID19 pandemic, we often notice these older, but still effective, rules are not being respected by all in social networks all around the globe. It is enough for a handful of people from a network to not wear masks for the disease to gradually reach more and more people. This leads to a major problem, because if the daily incidence surpasses the treatment capacity, it will overwhelm the 
healthcare system with detrimental consequences for medical care of infected individuals and increased mortality and morbidity. (Catching, 2021, 4) This situation could be seen in Italy ${ }^{1}$ and Romania ${ }^{2}$ during the COVID-19 pandemic. During an analysis of masks' efficacy, it has been discovered that it could range "anywhere from 20 to $80 \%$ for cloth masks, with $\geq 50 \%$ possibly more typical (and higher values are possible for well-made, tightly fitting masks made of optimal materials), 70-90\% typical for surgical masks, and $>95 \%$ typical for properly worn N95 masks" (Eikenberry et al, 2020, 298).

Further, we shall discuss the validity of four movies regarding real-life practices, behaviors and decisions, whilst implementing the ideas exemplified above.

\section{How imagination may become reality}

The first three movies we will center our attention on are Contagion (2011) Outbreak (1995) for their focus is how the world shifts to combat a high infectivity and mortality rate disease. The way the infection bursts and spreads, the steps the decision-makers take, population's reactions, the implication of military control and ultimately, solving the issue will be studied. We will also discuss Quarantine (2008), which focuses on a smaller scale of events. However, the last movie, It Comes at Night (2017), will give a glimpse to a different kind of situation, where the spreading of the virus could not be contained. Therefore, the focus will not be on the protocol following an outbreak, but on the mechanism and psychology of a social network during one.

Contagion (2011) tells the story of a bat-borne virus, MEV-1, that destroys the peace and quiet of the world. The first person we are introduced to, Beth Emhoff, is in the middle of interacting with different kinds of groups. She is one red dot in the green of the social network, as she is the index case (Patient 0). This brings an insight to the importance of interaction in the network, and to one of its immediate characteristics - it is unavoidable. The struggle to restrict social interaction brings forth the issue of families, where spreading a disease is extremely easy. We see that happening in the movie in the Emhoff family, as the mother and son die, while the father discovers he is immune.

Meanwhile, the Centers of Disease Control and Prevention (CDC) begin tracing the path of the virus - every person coming in contact with the first case discovered becomes a priority. Mapping the disease through the interactions a person becomes a priority and one of the first steps to be taken in understanding how the issue of the virus is evolving. We can see the same approach, but at a smaller scale during the Thomashefsky Case, where the social history of the woman who first came in with a case of Hepatitis $\mathrm{C}$ is meticulously reconstructed - from every place she visited to the people she came in contact with.

One of the most important scenes is the one where the father, Mitch and the daughter go into a store, where they encounter an infected woman that uses no means to protecting herself or the others. She coughs over the products and towards people around her, becoming a Superspreader. The behavior she exhibits is accurate, for we can also notice the same kind of carelessness in some cases during the COVID-19 pandemic.

\footnotetext{
${ }^{1}$ A.N: Italy faced excess mortality and morbidity during the pandemic - this is illustrated by the analysis of 2020 , when the excess mortality reached 15,6\%. (Dorrucci, Minelli et al, 2021,3) and by the rise in weekly infectivity cases from the $9^{\text {th }}$ of November, reaching 19, 002. (WHO, 2021)

2 A.N: In Romania, the excess mortality reached 62,6\% in November 2020. Nota bene: Excess mortality is expressed as the percentage rate of additional deaths in a month, compared to a "baseline" in a period not yet affected by the pandemic. The baseline adopted consists of the average number of deaths that occurred in each of the 12 months during the period 2016-2019. (Eurostat, 2021). Regarding confirmed COVID-19 cases, by $11^{\text {th }}$ of November 2021 there can be identified 90,183 cases per million people. (Our World in Data, 2021).
} 
STRATEGIES XXI International Scientific Conference

The Complex and Dynamic Nature of the Security Environment

Chaos is an element I find extremely important in the situation of an outbreak, as it brings with itself uncertainty. The protocol seems simple to follow - stay inside, stay calm, limit social contact, be careful not to infect and not to be infected while a cure is in developing. But some people are disobeying of the rules and have proven to be quite selfish in these situations. Hence, the first instinct is self-preservation, causing people to do anything to survive, even if it is in detriment of another. We see the effects of panic and desperation clearly, mirrored into reality.

During the start of the COVID-19 pandemic, in 2020, the world found itself in a similar situation when stores were assaulted by the population, looking to stock up as many items as possible. The same chaos can be seen at a larger scale during the movie, while entire cities enter lockdowns and people try to leave in order to escape both the disease and restrictions that follow.

Quarantine (2008) is focused on a news reporter, Angela Vidal and her cameraman who are documenting the work of the Los Angeles Fire Department. An emergency call brings them to an apartment building where screams and loud sounds were reported, and unbeknownst to them, a place riddled with a virus similar to a mutated form of rabies.

The first action towards containing the virus to be witnessed is locking down the building. No one can get in or out. The purpose of this action is to stop a future disaster by separating the infected ones from the social network, making it impossible for them to infect others. Separating individuals entirely from the network has proven itself effective, especially during the lack of a vaccine, and the military plays a major role towards maintaining the severance.

Being stuck inside, the firefighters ask the tenants to group. Scrutinizing this decision, we can deduce that by gathering all the people in the same room we are putting the uninfected in danger. They do not know what they are facing and the decision to bring together the people of the apartment building can cause the infection of all. Keeping the tenants separated in their apartments would have been the best solution for a positive outcome, as even the rabid would not escape the confinements. The corroboration of the statements is offered later during the movie, when a mother and daughter show symptoms.

After dealing with threats when they try to leave, the CDC sends two officers in hazmat suits to analyze the situation from inside. They decide to cuff the injured people as a safety measure, which is a benefiting decision since the virus makes them aggressive. However, it does not assure their safety, as one of the CDC officers is bitten and infected. Shortly after this scene the mapping of the virus is revealed, as well as the index patient - a dog, that was taken to the veterinary and infected other dogs, who in exchange turned aggressive and bit their owners, transmitting the mutated rabies. Afterwards, the original infected dog is traced back to the apartment building by the $\mathrm{CDC}$, resulting in the lockdown. We can consider that the mapping of the virus is accurate, but it was relatively slow.

Furthermore, facing an unknown virus and seeing themselves under lockdown, chaos ensures. We see the people trapped in the building not thinking clearly. The remaining people of the group tie the infected mother of the girl to the staircase, thus blocking the narrow hallway, restricting the space even more. They have successfully trapped themselves between a room with rabid humans, an exiguous hallway and a staircase that leads to more infected tenants. The decision to sedate the little girl, now fully into a rabid state, proves itself faulty, as that means they had to go to the next floor, pass the woman cuffed to the stairways, and enter a space filled with rabid tenants. This choice serves as a turning point due to the fact that they are caught between the newly infected couple of people they sent to the next floor and the rabid CDC officer that managed to escape through a poorly barricaded door. 
The chaos caused by the group's deficient decisions and the lies the rest weave to save themselves, knowing they are infected, leads to the final of the movie. In the end, no one manages to escape the building, succumbing to the mutated disease that is discovered to be named the Armageddon Virus. In this case, becoming immune was an impossible task, as rabies cannot be cured after symptoms start surfacing, and the virus takes only a few hours to fully take over.

Outbreak (1995) has a different approach to the other two, being focused even more on the decision-making necessary in such situations and the involvement of the military. As soon as the Motaba virus emerges in South Sudan, two U.S. Army Officers make the decision to keep it a secret and contain it by destroying the small camp of infected soldiers. Considering the $100 \%$ mortality rate and lack of vaccine, the morally difficult decision drops the possibility of a devastating outcome. In this case, the immunity of the remaining population was acquired through the death of the infected.

However, the Motaba Virus resurfaces through a capuchin monkey, which causes a chain reaction. The situation takes a turn for the worse when it mutates into a virus that spreads in a similar manner as Influenza. The inspiration for the disease is the Ebola virus, which emerged in 1976 in Africa and became a global epidemic within months during 2014- 2016.

A significant scene is the one when the United States Army Medical Research Institute and its levels are presented. On the last level, containing high mortality viruses, we see one of the workers take off her mask before leaving the area. Since the virus can be all over the gear, it must be carefully disposed of, and taking off a mask in the laboratory is not a wise choice. It gives us an insight on how much of a small mistake can impact a greater level.

Another important scene is the one where an infected man enters a cinema serving area and asks for water, whilst not wearing a facemask. The superspreaders are very common during the movie, most of the sickness being transmitted due to wrong behavioral reasons. This leads to a situation mentioned previously - the inevitable overwhelming of the healthcare systems. The virus continues to spread through the hospitals due to the deluge of patients. Civil unrest is also depicted, chaos starting engulfing the population desperate for a cure.

The CDC's portrayal is of great importance. They try to locate the origin of the virus in order to create a social history of the deadly disease. The mission seems impossible, as there have been numerous transports of capuchin monkeys. Not only do they have to find the right one, but to also identify the first monkey to have been infected. The models of the Motaba Virus they create are very accurate and show how the healthy cells are slowly taken over, making it impossible for them to reproduce.

The movie brings a different approach through the origins of the Motaba Virus, which is revealed to have been constructed as a bio-weapon. In the end, a vaccine is released and the pandemic is quelled. The $100 \%$ mortality rate can also be considered a hinderance in the process of spreading, as it is possible for the person to die before they get to infect others, but the high infectivity level can also lead to a situation when people are being rapidly infected, even in a short amount of time.

On the other hand, the movie It Comes at Night (2017) shifts our focus from what happens in the bigger picture to the smaller pieces of the puzzle. After an unnamed disease leaves Earth in ruins, a couple and their son's survival is related. An important detail is the place where they decide to live, a cabin deep in the woods - a self-sufficient and most importantly, secluded, decision. By limiting the need to interact with others either through avoiding needing stores and communicating to individuals, the family has successfully cut itself from the network and lowered the chances of being infected. Secluded and stocked up houses are a big part of the survivalist movement, where preparing for emergencies either through long-term or short-term decisions is meant to give an advantage in case of catastrophe. 
STRATEGIES XXI International Scientific Conference

The Complex and Dynamic Nature of the Security Environment

One of the important scenes we see early in the movie is the when the grandfather gets sick, as he is immediately killed and his body is burned in order to prevent the transmission of the virus.

A relevant scene, and the catalyst of their downfall is accepting another family in their home. Such a dangerous decision comes with consequences, as they do not know if the people they are about to welcome in their own home are infected or not. Admittedly, in an almost apocalyptic world, defense against other groups is easier when there are more people, but so is spreading the virus. Knowing that of the others find out you are infected would bring an even more premature death, and death is one of humanity's greatest fears, one individual's judgement can be clouded, putting at risk the entire group.

There are two families now living under the same roof: the couple Paul and Sarah and their son, Travis, and the newcomers which consist of the couple Will and Kim, together with their son, Andrew.

The turning point of the movie is when Travis leaves the safety of the house and brings back their missing dog, leaving the door unlocked. Paranoia and fear start changing the dynamic of the social network that was created between the two families. They start doubting and suspecting each other, leading to them quarantining in separate rooms. This scene represents one of the last rational decisions before fear of infection. The human behavior under the looming threat of being infected and killed is perfectly portrayed, reaching its zenith when Andrew is suspected and they decide to kill the newcomers. By eliminating him from the network, just like in the case of the grandfather, they boost their chances at survival. At the same time, it is never revealed if they were indeed infected or the desperation and selfpreservation took over the household. Travis soon follows, dying because of the virus. The movie ends with a scene showing the sickly-looking parents standing at the table.

\section{Responding to a crisis}

One key factor that binds the four movies consists is the existence of errors: in social interactions, mappings, practices and so on. Errors have become a part of human life. Errors in judgment can be seen as the turning points in every movie previously analyzed: the choice to group with people when there is a possibility for them to be infected, removing masks at the wrong time or even not wearing any. But we also see another side that is reflected in our world - malpractice. As shown in Contagion (2011), Patient 0 is infected as a result of the cook not washing his hands. A similar situation can be seen regarding the Thomashefsky Case (2015), that we have previously only analyzed as a mapping example. The lack of gloves, unprepared staff, undated blood vials and chaotic placement of dirty vials besides clean ones was enough evidence to shut down the clinic. Officials notified the patients who received injections from the doctor from 2008 to 2015. (Staff, 2015)

Social networking is accurately represented, especially comparing movies with reality. We may take COVID-19 as an example - after the outbreak, authorities of the first affected countries imposed quarantining along with certain restrictions, but under different intensity and results. The Oxford Covid-19 Government Response Tracker was successful in representing in a chart the Stringency Index of various countries, as it can be seen in Figure no. 1: 


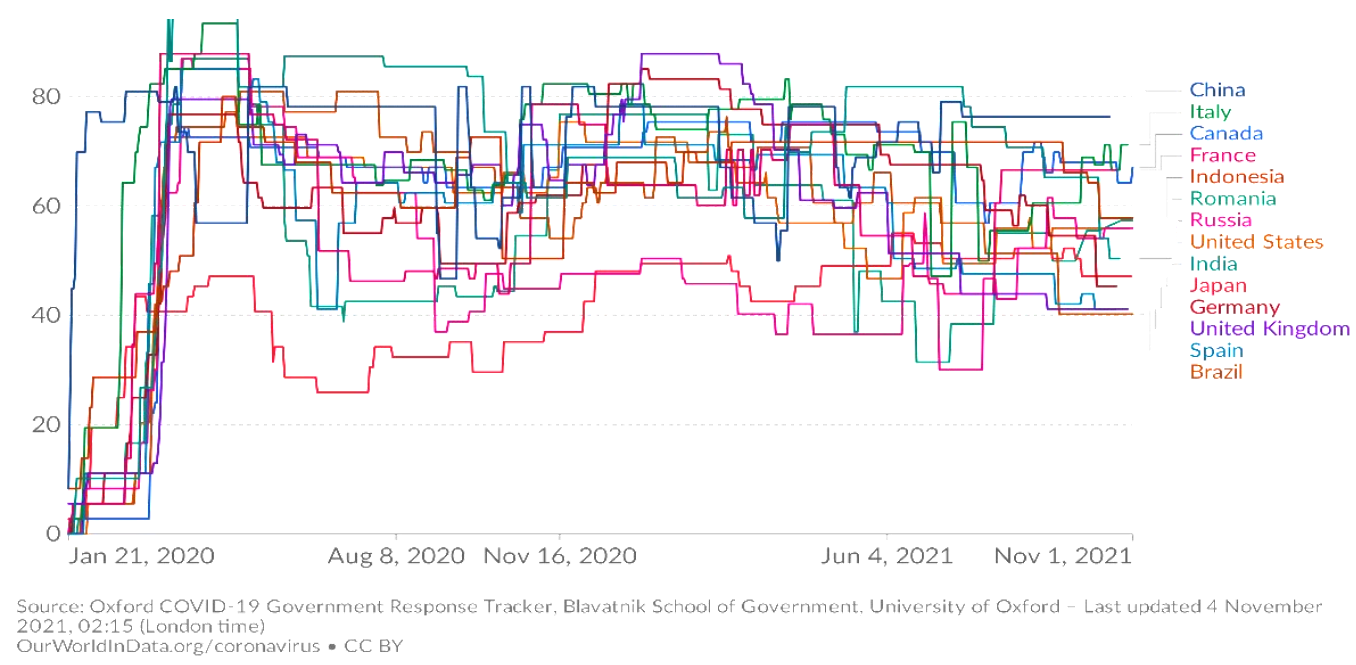

Figure no.1: COVID-19 Sringency Index (OxcCGRT)

We can see that China and India maintaied the strictest policies against Covid-19 for a very long time, until aproximately the $20^{\text {th }}$ of September, 2020. Italy, the United Kingdom and Germany take their place until the $11^{\text {th }}$ of May, 2021. Despite the complicated and changing positions on the chart, we notice that China, India and Italy are the most constant out of the 10 countries tracked. The scale rates the severity of the restricitons imposed.

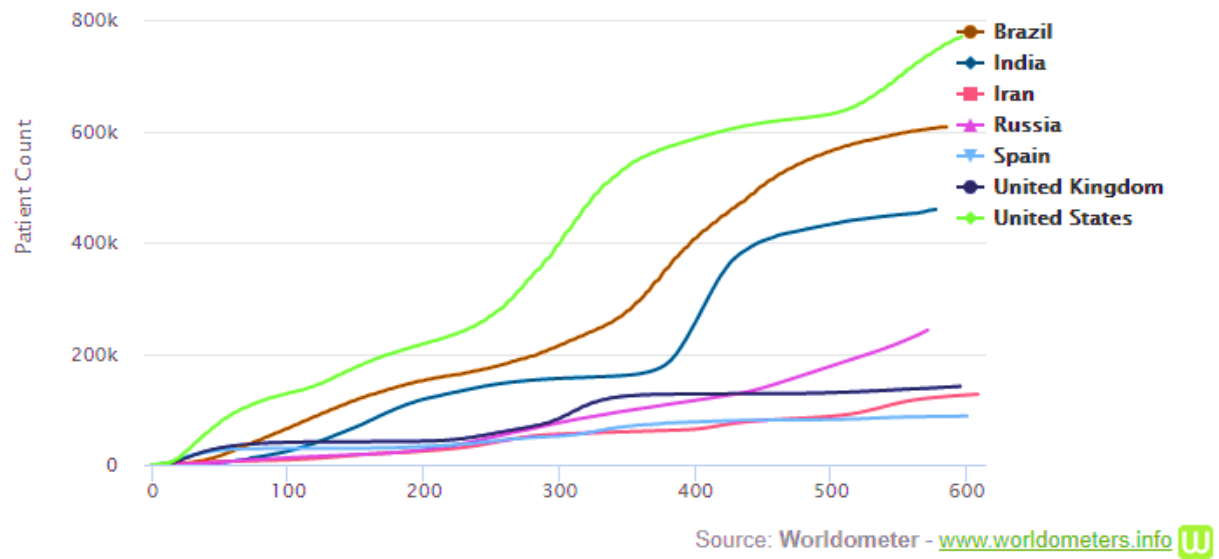

Figure no. 2: Cumulative number of deaths, by number of days since 100 deaths (Worldometers)

For a better understanding we may compare the Stringency Index with the mortality graph in Figure no. 2. It can be easily observed that the United States, which imposed lighter restrictions, also had a higher infectivity rate, especially compared to the United Kingdom's harsh approach at that point that led to low mortality and infectivity rates. Following the REUTERS COVID-19 global tracker we can also notice that Asia and the Middle East have a lower infectivity and mortality rate (at its peak, around 700k infections and respectively $12 \mathrm{k}$ deaths) compared to Europe, who peaked at little over 800k infections and 17k deaths. 
STRATEGIES XXI International Scientific Conference

The Complex and Dynamic Nature of the Security Environment

We can deduce that separating individuals to decrease the rate of infections is effective, but only as long as the indications and separations are followed. As previously mentioned, there are people that are by behavior what we know as superspreaders. As we have seen during the COVID-19 pandemic so far, superspreaders are commonly the individuals who do not follow the restrictions imposed. Hence, the probability they become infected and pass it on others is notably higher.

Medical Martial Law in not to be ignored, although it may be considered a tricky concept to define in the case of pandemics, as it refers to the direct involvement of the military in keeping order and making sure every curtailment is followed. We have seen it happen in the movies Contagion, Quarantine and Outbreak as a last resort to keeping the population calm in the face of something they had never experienced before. Although we have seen the Martial Law enacted in order to quell riots and sometimes even social unrest after attacks ${ }^{3}$, a medical Martial Law has yet to be enacted. Essentially, when the government fails, the military is tasked with assuming responsibility, even if that means taking initiative in stopping the spread of a disease. That does not mean, however, that the military cannot partake in overseeing vaccination campaigns. In Canada, Brigadier General Krista Brodie is tasked with overseeing the delivery and distribution of vaccines.

Vaccine campaigns constitute an important matter to put under a magnifying lens. In the movies mentioned above (excluding It Comes at Night and Quarantine) we can clearly see an ideal scenario - everyone is willing to go through inoculation. One may argue that the circumstances differ, as the lethality rate of the diseases mentioned is $100 \%$, but it is also impossible to ignore the death count our present pandemic has. This reluctant behavior has been attributed to a large number of factors, such as misinformation and disinformation, mistrust both in the government and the vaccine itself, rumors, insufficient medical data available at the time and so on. World Health Organization (WHO) created a chart of recommended interventions in order to aid states in managing the pandemic that can be seen in Figure no. 3 .
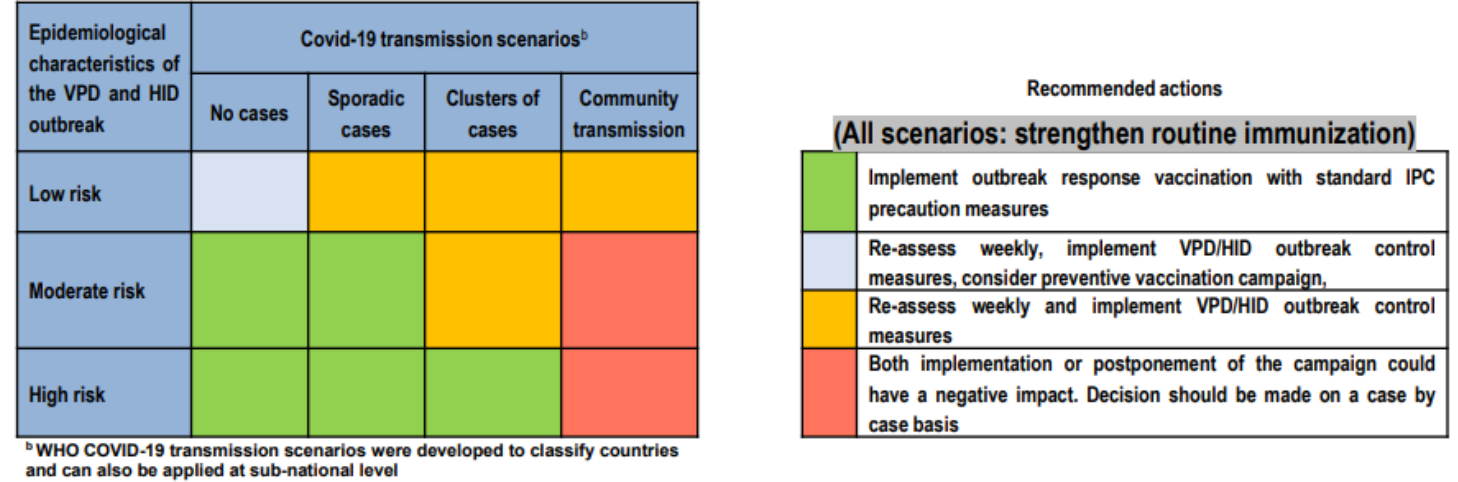

Figure no. 3: Recommended actions regarding COVID-19 transmission scenarios, (WHO)

*VPD - Vaccine Preventable Disease; **HID - Highly Infectious Disease

Despite the attempts at community engagement and displaying information, we can notice that the recommended course of action was not always followed, and combining this with a general misinformation we can see the contributing factors leading to wariness. We can

\footnotetext{
${ }^{3}$ A.N: There are numerous examples of martial laws being declared, such as: The San Francisco martial law from 1906 after an earthquake and the martial law that followed the attack on Pearl Harbor in 1941. By studying these examples, it can be easily seen how the martial law can be applied on different situations, be it a natural disaster or war.
} 
take as an example the rumors circulated by Taliban that Western vaccines cannot be trusted, leading to a low vaccination rate at the Pakistan borders. (PLOS, 2011). We can add to the growing list of concerns some failed drug trials, such as Trovan by Pfizer, which was supposed to cure the meningitis outbreak in 1996 Africa. (Smith, 2011; Lenzer, 2006, 1233; BBC, 2011)

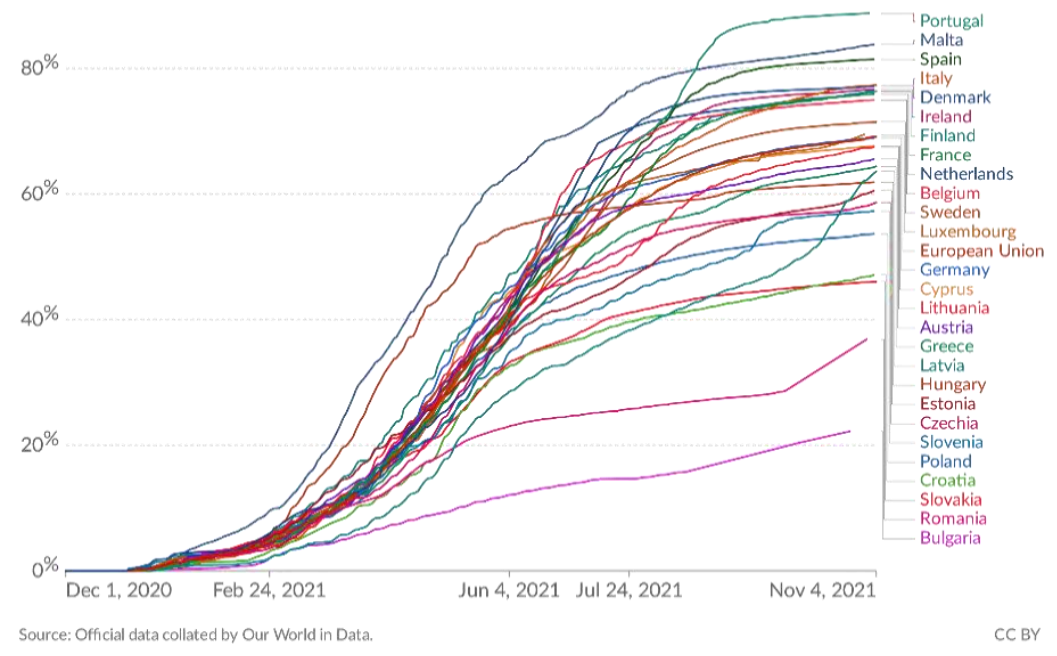

Figure no. 4: People who received at least one dose of COVID-19 vaccine (Our World in Data)

As we can see, there is a contrasting difference between what is portrayed in movies and reality.

Lastly, along with issues regarding the management of the COVID-19 pandemic there comes another major concern - the psychological state of the citizens. As mentioned previously, in such situations it is not uncommon for an individual to lose rational thinking, maybe even becoming paranoid. Unfortunately, fear induced by extensive mass media coverage of the pandemic may contribute to this as well. There is also the issue of depression due to lack of social interaction, fear of contagion, uncertainty regarding the future, economic difficulties. Moreover, we can notice an increase in anxiety and divorce rates ${ }^{4}$ around the world. It is an interesting matter to analyze.

On the positive side, taking Germany as an example, studies concluded that suicide rates were at their lowest during severe restrictions - this has been attributed to the strengthening of familial bonds during lockdowns. (Radeloff, Papsdorf et al, 2021, 3) It is also worth mentioning that this has also been attributed to the increase in social cohesion during threats (Durkheim, 2005; Claassen et al, 2010). Howbeit, this may not be the case in every country.

\section{Conclusions}

Out of all the movies, Contagion shows the best representation of an actual pandemic, easily being compared to historical experiences. The mapping and analysis of the virus is accurately portrayed, and so are the decisions taken and the reactions of the citizens.

As we have seen, there were similarities and differences between how humanity imagined combating a pandemic and the actuality of present-day struggles. The psychological and social impacts of such a situation are outlined in both reality and movie-making, but that

\footnotetext{
${ }^{4}$ A. N.: For instance, the divorce rates in both China and USA grew exponentially during the pandemic. (Prasso, 2020; BBC, 2020)
} 
STRATEGIES XXI International Scientific Conference

The Complex and Dynamic Nature of the Security Environment

brings us to certain worries that linger: oftentimes, technology is not able to fully aid us in our quest of eradicating disease. And this is a starting point for even more premises.

We have noticed the tendency towards developing weapons of mass destruction, and biowarfare may be an important element in the future. Whilst a nuclear bomb can be easily traced, a virus is a lot easier to be used in more than one place at once, while guaranteeing anonymity behind a wall of assumptions. This idea is not only explored by Outbreak movie, but also in books such as Future War and Defence of Europe by John Aleen, Fredrick Hodges and Julian Lindley-French, where COVID-19 is reused years later as a biological weapon.

Times are changing, and in the future we may look at a different approach towards pandemic management, curing disease and the culture of infection prevention.

\section{BIBLIOGRAPHY:}

***, BBC NEWS, 2011, Pfizer: Nigeria drug trial victims get compensation, URL: https://www.bbc.com/news/world-africa-14493277

***, BBC, 2020, Why the pandemic is causing spikes in break-ups and divorces, URL: https://www.bbc.com/worklife/article/20201203-why-the-pandemic-is-causing-spikesin-break-ups-and-divorces

***, Eurostat, 2021. Excess mortality - statistics. URL: https://ec.europa.eu/eurostat/statisticsexplained/index.php?title=Excess_mortality_-_statistics\&oldid=509982\#

Excess_mortality_in_the_European_Union_between_January_2020_and_August_2021

***, Our World in Data. 2021. Cumulative confirmed COVID-19 cases per million people, URL: https://ourworldindata.org/coronavirus/country/romania

***, Our World in Data, People who received at least one dose of COVID-19 vaccine, URL: https://ourworldindata.org/explorers/coronavirus-data-explorer?yScale=log\&zoom ToSelection $=$ true $\&$ facet $=$ none $\&$ pickerSort $=$ desc $\&$ pickerMetric $=$ total_vaccinations $\&$ hid eControls $=$ true $\&$ Metric $=$ People+vaccinated $\&$ Interval $=$ Cumulative $\&$ Relative + to + Popul ation $=$ true \&Align+outbreaks $=$ false \&country=European+Union $\sim$ ESP $\sim$ FRA $\sim$ DEU $\sim$ POL $\sim \mathrm{NLD} \sim \mathrm{HUN} \sim \mathrm{ROU} \sim \mathrm{BEL} \sim \mathrm{PRT} \sim \mathrm{GRC} \sim \mathrm{CZE} \sim \mathrm{AUT} \sim \mathrm{SWE} \sim \mathrm{DNK} \sim \mathrm{IRL} \sim \mathrm{HRV} \sim \mathrm{BGR} \sim \mathrm{SV}$ N $\sim$ LVA $\sim$ EST $\sim$ CYP MLT LUX $\sim$ SVK L LTU ITA FIN

***, World Health Organization, 2021, Italy, URL: https://covid19.who.int/ region/euro/country/it

***, World Health Organization, Framework for decision-making: Implementation of mass vaccination campaigns in the context of COVD-19, URL: https://www.who.int/docs/ default-source/coronaviruse/framework-for-decision-making-implementation-of-massvaccination-campaigns-in-the-context-of-covid19-slide-deck.pdf?sfvrsn=438dccc8_2

ALEEN, John, HODGES, Fredrick, 2021, Lindley-French, Julian, Future War and Defence of Europe, USA: Cambridge University Press.

CATCHING, A., CAPPONI, S., Yeh, M.T., 2021, Examining the interplay between face mask usage, asymptomatic transmission, and social distancing on the spread of COVID-19. Sci Rep 11, 15998.

CAVAILLON, Jean-Marc, OSUCHOWSKI, Marcin, COVID-19 and earlier pandemics, sepsis, and vaccines: A historical perspective, Elsevier B.V., Journal of Intensive Medicine, 2021.

CLAASSEN, CA, CARMODY, T, STEWART, SM, BOSSARTE, R.M, LARKIN, GL, WOODWARD, WA, TRIVEDI, MH, 2010, Effect of 11 September 2001 terrorist attacks 
in the USA on suicide in areas surrounding the crash sites. The British Journal of Psychiatry: The Journal of Mental Science.

DIETZ, Klaus, HEESTERBEEK, J.A.P., 2002, Daniel Bernoulli's epidemiological model revisited, Mathematical Biosciences 180, 2 Elsevier Science Inc.

DORRUCCI, Maria, MINELLI, Giada, BOROS, Stefano, MANNO, Valerio, PRATI, Sabrina, BATTAGLINI, Marco, et. al. 2021, Excess Mortality in Italy During the COVID-19 Pandemic: Assessing the Differences Between the First and the Second Wave, Year 2020, Frontiers in Public Health, Volume 9, DOI: 10.3389/fpubh.2021.669209

DOWDLE, Erick, John, October 2008, Quarantine, Sony Pictures Releasing.

DURKHEIM, Emile, 2005, Suicide: A Study in Sociology, e Taylor \& Francis e-Library.

EIKENBERRY, Steffen, MANCUSO, Marina, IBOI, Enahoro, PHAN, Tin, et al. 2020, To mask or not to mask: Modeling the potential for face mask use by the general public to curtail the COVID-19 pandemic, Infectious Disease Modelling, School of Mathematical and Statistical Sciences, Vol. 5.

GLASS, L.M., GLASS, R.J., 2008, Social contact networks for the spread of pandemic influenza in children and teenagers, BMC Public Health.

GLASS, Robert, J; GLASS Laura M., Beyeler Walter E, Min H. Jason, 2006, Targeted social distancing design for pandemic influenza, Emerging Infectious Diseases, Vol. 12, No. 11, November.

LENZER, Jeanne, 2006, Secret report surfaces showing that Pfizer was at fault in Nigerian drug tests, BMJ (Clinical research ed.) vol. 332

LEWIS, Michael, 2021, The Premonition: A Pandemic Story, UK: Penguin Books.

PETERSEN, Wolfgang, March 1995, Outbreak, Warner Bros. Entertainment Inc.

PLOS, Speaking of Medicine and Health, 2011, Failed vaccine campaigns are a global issue, URL: https://speakingofmedicine.plos.org/2011/09/12/failed-vaccine-campaigns-are-aglobal-issue/\#_ENREF_1

PRASSO, Sheridan, 2020, China's Divorce Spike Is a Warning to Rest of Locked-Down World, URL: https://www.bloomberg.com/news/articles/2020-03-31/divorces-spike-in-chinaafter-coronavirus-quarantines

RADELOFF, D, PAPSDORF, R, UHLIG, K, VASILACHE, A, PUTNAM, K, von KLITZING, $\mathrm{K}, 2021$, Trends in suicide rates during the COVID-19pandemic restrictions in a major German city, Cambridge University Press, Epidemiology and Psychiatric Sciences 30.

Reuters, COVID-19 Global tracker, URL: https://graphics.reuters.com/world-coronavirustracker-and-maps/

SHEYNIN, O.B., 1977, D. Bernoulli's work on probability, in: M. Kendall, R.L. Plackett (Eds.), Studies in the History of Statistics and Probability, vol. II, London.

SHULTS, Edward Trey, April 2017, It Comes at Night, A24.

SMITH, David, 2011, Pfizer pays out to Nigerian families of meningitis drug trial victims, URL: https://www.theguardian.com/world/2011/aug/11/pfizer-nigeria-meningitis-drugcompensation

SODERBERGH, Steven, September 2011, Contagion, Warner Bros. Pictures

Staff, Indy, 2015, Six Thomashefsky Patients Test Positive for Hepatitis, Santa Barbara Independent, URL: https://www.independent.com/2015/04/21/six-thomashefskypatients-test-positive-hepatitis/ 